\title{
Proteomics in Detection and Monitoring Chronic Lung Diseases: The Human Nasal Epithelium as a Molecular Model
}

\section{Tânia Simões*, Nuno Charro, Bruno M. Alexandre and Deborah Penque*}

Laboratório de Proteómica, Departamento de Genética, Instituto Nacional de Saúde Dr. Ricardo Jorge, Lisboa, Portugal

Keywords: Chronic obstructive lung diseases; Upper and lower airways; Nasal epithelium; Proteomics; Biomarkers

Asthma and chronic obstructive pulmonary disease (COPD) are major causes of mortality and morbidity worldwide. The current state-of-art diagnosis and management schemes are suboptimal for both diseases as the incidence of asthma has risen by $250 \%$ over the last two decades and COPD is estimated to become the third leading cause of death worldwide within the next decade. Additionally, these diseases represent a very important threat to global economies in direct and indirect medical costs and lost working days [1,2]. Asthma is a chronic inflammatory disorder of the airways associated with airway hyperresponsiveness that leads to recurrent episodes of wheezing, breathlessness, chest tightness and coughing. These episodes are usually associated with widespread, but variable, airflow obstruction within the lung [1]. Chronic airflow obstruction is also characteristic of COPD but, in contrast to asthma, is not fully reversible, even under the action of bronchodilators, and is usually progressive. A combination of small airway disease -obstructive bronchiolitis - and parenchymal destruction - emphysema, leads to COPD clinical manifestation [2]. A number of factors influence a person's risk of developing these lung diseases, which include host factors, primarily genetic, and environmental factors, such as allergens and tobacco smoke in asthma and COPD, respectively [1-3].

Chronic lung disease is the major cause of morbidity and mortality among patients suffering from Cystic Fibrosis (CF), the most common autosomal recessive disease in Caucasian population [4]. Mutations in the CF transmembrane conductance regulator (CFTR) gene disrupt a cAMP-regulated chloride channel - the CFTR protein - which is mainly present at the apical plasma membrane of epithelial cells lining organs such as the sweat glands, pancreas and airways [5]. Although impressive progress in the elucidation of the genetic and molecular basis of CF has been done, no effective therapy exists to control progressive lung deterioration in CF patients [6]. The lung disease in $\mathrm{CF}$ is characterized by thick mucus, recurrent airway inflammation and chronic bacterial infections, which result in airway narrowing that ultimately lead to fatal respiratory failure [4]. Since airflow obstruction is a component of CF' lung disease, as it is in asthma and COPD, these diseases are also categorized as obstructive lung diseases, in opposition to restrictive lung diseases. In these obstructive diseases, a vicious cycle of repeated airway inflammation is associated with structural tissue "remodeling" inappropriate to the maintenance of normal lung function [7], suggesting that similar molecular pathways may be involved in the pathogenesis of these diseases. Environmental factors and modifier genes other than CFTR genotype determine progression of lung disease in CF $[4,5,8]$. Some of these CF modifier genes (e.g., TGF1, TNFinterleukin genes) [8], including the CFTR gene itself, have been described as a putative genetic risk factors for asthma and COPD [9-16]. However, remains to be elucidated how the dysfunction of a protein such as CFTR, the repeated exposure to tobacco smoke or allergen-induced cellular responses, despite involving the same tissue and presumably sharing some similar molecular pathways, are able to cause distinct pulmonary diseases like CF, COPD and asthma, respectively. To get further insights on the pathogenic mechanisms underlying these obstructive pulmonary diseases, a more complete description of normal molecular physiology of the airway system is required.

Proteomics can offer a comprehensive cell/tissue proteome characterization using advanced tools such as high performance liquid chromatography, mass spectrometry and bioinformatics. Clinical proteomics, an emerging field of proteomics, aims to identify specific protein profiles of diseases - biomarkers - and apply this knowledge to better understand, diagnose and manage diseases [17]. To solve a specific clinical problem within the context of a clinical study, patients with other diseases/disorders mimicking features of the studied disease must be included in a proteomic study [17]. Therefore, it is attractive to consider asthma and COPD together with CF in a comparative proteomics study to identify specific biomarkers for any of these particular diseases.

Another challenge to the clinical proteomics field is the appropriate selection and collection of biospecimens for a specific clinical problem. To study chronic lung diseases, several biospecimens have been used to access the airway microenvironment, including induced sputum, bronchoalveolar lavage, nasal lavage fluid, exhaled breath condensate and, in less extent, bronchial and lung biopsies that result from an extremely invasive procedure.

We have proposed the use of nasal epithelium (NE) collected by nasal brushing as a molecular airway model for comparative proteomics studies of chronic respiratory diseases. Our group has demonstrated that nasal brushing, a painless and non-invasive procedure, is capable of yielding numerous and well-preserved dissociated cells that are representative of the human superficial respiratory mucosa. In fact, about $85 \%$ of cells collected by nasal brushing are epithelial cells: nonciliated and ciliated columnar cells, basal and goblet cells [18] (Figure 1). We have demonstrated in previous works, the utility of these cells in the study of the monogenic disease cystic fibrosis, namely by twodimensional electrophoresis (2D-gel) or SELDI-TOF based proteomics

*Corresponding authors: Deborah Penque, PhD, Laboratório de Proteómica, Departamento de Genética, Edifício INSA II, Instituto Nacional de Saúde Dr. Ricardo Jorge, INSA, I.P., Avenida Padre Cruz, 1649-016 Lisboa, Portugal, Tel: +351 21750 8137; Fax: +351 1121752 6410; E-mail: deborah.penque@insa.min-saude.pt

Tânia Simões, PhD, Laboratório de Proteómica, Departamento de Genética, Edifício INSA II, Instituto Nacional de Saúde Dr. Ricardo Jorge, INSA, I.P., Avenida Padre Cruz, 1649-016 Lisboa, Portugal; Tel: +351 21750 8137; Fax: +351 1121752 6410; E-mail: tania.simoes@insa.min-saude.pt

Received December 24, 2011; Accepted February 22, 2012; Published February 26, 2012

Citation: Simões T, Charro N, Alexandre BM, Penque D (2012) Proteomics in Detection and Monitoring Chronic Lung Diseases: The Human Nasal Epithelium as a Molecular Model. J Aller Ther S7:004. doi:10.4172/2155-6121.S7-004

Copyright: $\odot 2012$ Simões T, et al. This is an open-access article distributed under the terms of the Creative Commons Attribution License, which permits unrestricted use, distribution, and reproduction in any medium, provided the original author and source are credited. 


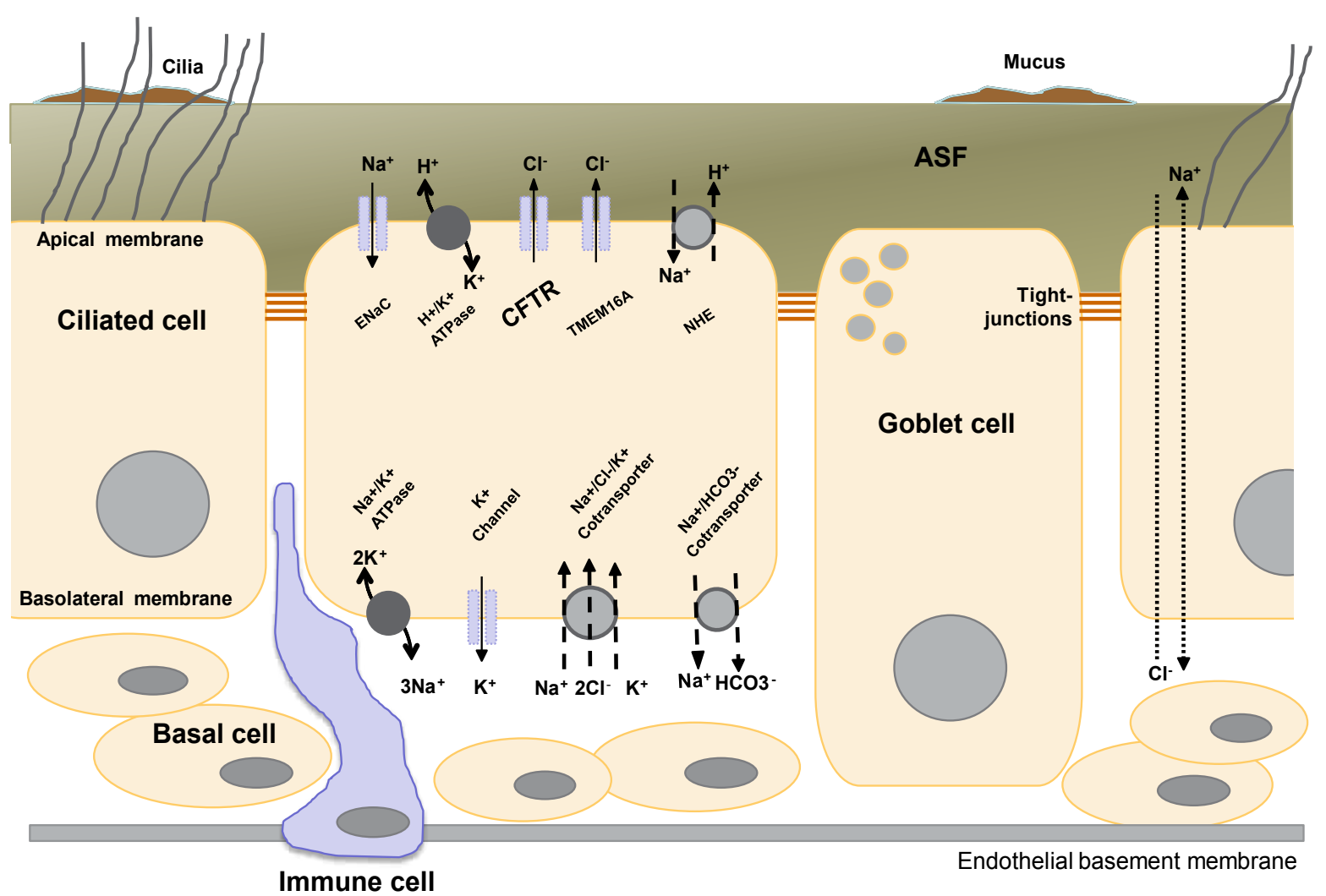

Figure 1: Schematic representation of the airway epithelia. The major cell types in the proximal airways are represented along with their most important ion transport systems. The airway surface fluid (ASF) is the fluid in which cilia moves to enable mucociliary clearance. The correct depth of ASF is maintaned by regulated absorption and secretion of ions and water. The epithelial sodium channel (ENaC) and the $\mathrm{Na}^{+} / \mathrm{K}^{+} \mathrm{ATPase}$ membrane proteins are involved in $\mathrm{Na} a^{+}$absortion. The TMEM16A (also known as anoctamin 1) and the cystic fibrosis transmembrane conductance regulator (CFTR) on the apical membrane and the sodium-potassium-chloride cotransporter (NKCC) on the basolateral membrane are involved in $\mathrm{Ca}^{2+}$ - and cAMP-mediated $\mathrm{Cl}$ - secretion, respectively. The inward $\mathrm{Na}^{+}$gradient established by plasma membrane $\mathrm{Na}^{+} / \mathrm{K}^{+}$-ATPase pumps also propels the countertransport of $\mathrm{H}^{+}$by sodium/proton exchanger (NHE) which along with bicarbonate cotransporters extrude the excess of acid accumulated by cellular metabolism and by various $\mathrm{H}^{+}$(acid equivalents) leak pathways conducts to intracellular $\mathrm{pH}$ maintenance.

$[19,20]$. In a recent study in collaboration with National Cancer Institute, we conducted the most complete proteomic characterization of human NE collected by brushing technique. We employed an improved subcellular fractionation method to obtain soluble and membraneenriched fractions followed by a high sensitive multidimensional protein identification technology to increase proteome coverage of this epithelium [21]. In total, a set of 1482 proteins were identified and functionally annotated using several databases, extending the actual knowledge of the proteome of NE microenvironment, which relied mainly on soluble proteins [22-24]. Out of those proteins, about 947 were identified as membrane-associated as confirmed by grand average hydropathy value index analysis, transmembrane protein mapping and annotations of primary location deposited in the Human Protein Reference Database. Molecular and cellular functional annotation of identified proteins, performed by Ingenuity Pathway Analysis, unraveled mechanisms and processes intimately correlated with a respiratory epithelium. The view of the epithelium as a physical barrier between the host and its environment regulating ion and water transport is supported by our study revealed a large number of proteins involved in structural stabilization of nasal epithelial cells via cytosqueletal components and transportation of molecules such as ions (Figure 1). Other functions were also found enriched in NE proteome, such as gel-phase protection, immunological defense, including innate immunity and immune regulation, and detoxification. These pathways are illustrated by several proteins such as mucins (e.g. MUC5AC,
MUC5B), LPS binding proteins (e.g. CAMP, BPI), Toll-like receptors (e.g. TLR3), leukocyte surface markers (e.g. CD47, CD59, CD14), possibly reflecting recruitment of inflammatory cells to this epithelium, and also ATP-binding cassette (ABC) transporters associated with the multidrug Resistance phenomenon (e.g. ABCC1 (or MRP1), $\mathrm{ABCC} 3$ and $\mathrm{ABCC} 4$ ) and proteins involved in drug and xenobiotics metabolism (e.g. ALDH9A1, NQO1, CES1, GCLC, CAT, GSTP1). Thus, our proteomics data reinforce the idea of the airway epithelium as a dynamic and multifunctional entity that act as central modulator of airway mucosal structure and function, being able to respond to environmental insults such as pathogen, allergen, and pollutant exposure through mechanisms of clearance, detoxification, immune regulation and regeneration $[25,26]$. Continued epithelial challenge to such environmental insults and impaired repair responses may lead to altered epithelial physical and functional barrier properties providing the mediator and growth factor microenvironment for persistence of inflammation and airway remodeling. This chain of events seems to play a major role in asthma, COPD and CF pathogenesis $[7,27,28]$. Moreover, we have observed that the proteome of human NE have extended overlay with that known so far for human bronchial mucosa [21]. This fact highlights the molecular similarities between upper and lower epithelia supporting the concept of united airways. In fact, all respiratory passages, from the nose to the terminal bronchioles, share histological and physiological similarities at epithelium level [29] reflecting their common susceptibility to environmental insults such as 
Citation: Simões T, Charro N, Alexandre BM, Penque D (2012) Proteomics in Detection and Monitoring Chronic Lung Diseases: The Human Nasal Epithelium as a Molecular Model. J Aller Ther S7:004. doi:10.4172/2155-6121.S7-004

Page 3 of 4

those reported before. This idea is reinforced by the well-documented relationship between allergic rhinitis and asthma (Passalacqua et al. 2001; Serrano et al. 2005; Rimmer et al. 2006; Braunstahl et al. 2007; Bourdin et al. 2009; Compalati et al. 2010) [29-34], which most clinical, epidemiological and biological data point for integrated management targeting epithelial cells.

As part of the NE proteome, we identified about 140 proteins previously associated with the development and/or progression of several respiratory diseases. For example, the two proteins inducible nitric oxide synthase (NOS2) and triosephosphate isomerase (TPI) have been associated with asthma [35] while myeloperoxidase (MPO) and lactotransferrin (LTF) have been involved in the development of Cystic Fibrosis [36]. This is also the case of the two key proteins, previously described in Cystic Fibrosis mouse model by our group, retinal dehydrogenase 1 (ALDH1A1) and aldehyde dehydrogenase (ALDH2). Along with ADH7, these are crucial enzymes in retinoic acid metabolism, a hormone known as important regulator of organ development and homeostasis, including lung [37]. To what COPD is concerned, we also identified in nasal epithelial cells three proteins reported to be differentially expressed in BALF of COPD patients - Neutrophil defensins 1 and calgranulin A and B - [38]. In sputum, the clara cell secretory protein (CCSP) was also reported as potential COPD biomarker [39].

In summary, we advocate that nasal epithelium is an attractive biospecimen to approach chronic obstructive lung diseases such as COPD, asthma and by CF using several technical strategies, namely clinical proteomics. Our extensive characterization of NE proteome supports previous evidence demonstrating the importance of airway epithelium to the normal physiology of the airway system. Additionally, we observed considerable similarities between this proteome and those expressed by bronchial epithelium, which is a target tissue on the diseases described above. This biological sample is easily collected by nasal brushing, which is well tolerated even by very young children, making possible its widespread use. The number of cells collected by this technique is appropriate for several biochemical analyses, including flux cytometry, enabling parallel evaluation of different cell types (epithelial and inflammatory cells) and multiple protein markers. Therefore, the implementation of a standard sampling procedure and performing comparative systematic analysis of CF/COPD/Asthma NE-Proteome, might conduct to a better understanding of specific molecular pathways associated with each of these diseases. The characterization and validation of the proteins specifically involved in identified molecular pathways, may ultimately serve as key biomarkers for improving diagnosis, staging and monitoring disease progression or treatment response.

\section{Acknowledgements}

Tânia Simões, Nuno Charro and Bruno Alexandre were supported by Fundação para Ciência e Tecnologia (FCT) fellowships. The present study was partially financed by FCT (research grant POCI/SAU-MMO/56163/2004), FCT-Poly Annual Funding and FEDER-Saúde XXI.

\section{References}

1. GINA (2010) Global Initiative for Asthma, Global Strategy for Asthma Management and Prevention.

2. GOLD (2010) The Global Initiative for Chronic Obstructive Lung Disease, Global Strategy for Diagnosis, Management, and Prevention of COPD.

3. WHO (2011) World Health Organization Report on the global Tobacco epidemic, 2011: warning about the dangers of tobacco.

4. Rowntree RK, Harris A (2003) The phenotypic consequences of CFTR mutations. Ann Hum Genet 67: 471-485.
5. Vankeerberghen A, Cuppens H, Cassiman JJ (2002) The cystic fibrosis transmembrane conductance regulator: an intriguing protein with pleiotropic functions. J Cyst Fibros 1: 13-29.

6. Schechter MS, Gutierrez HH (2010) Improving the quality of care for patients with cystic fibrosis. Curr Opin Pediatr 22: 296-301.

7. Sköld CM (2010) Remodeling in asthma and COPD--differences and similarities. Clin Respir J 1: 20-27.

8. Cutting GR (2010) Modifier genes in Mendelian disorders: the example of cystic fibrosis. Ann N Y Acad Sci 1214: 57-69.

9. Tiddens $H$, Silverman M, Bush A (2000) The role of inflammation in airway disease: remodeling. Am J Respir Crit Care Med 162: S7-S10.

10. Dahl M, Tybjaerg-Hansen A, Lange P, Nordestgaard BG (2005) Asthma and COPD in cystic fibrosis intron-8 5T carriers. A population-based study. Respir Res 6: 113.

11. Wood AM, Stockley RA (2006) The genetics of chronic obstructive pulmonary disease. Respir Res 7: 130.

12. Stankovic M, Nikolic A, Divac A, Tomovic A, Petrovic-Stanojevic N, et al. (2008) The CFTR M470V gene variant as a potential modifier of COPD severity: study of Serbian population. Genet Test 12: 357-362.

13. Kalsheker N, Chappell S (2008) The new genetics and chronic obstructive pulmonary disease. COPD 5: 257-264.

14. Dahl M (2009) Genetic and biochemical markers of obstructive lung disease in the general population. Clin Respir J 3: 121-122.

15. Dahl M, Nordestgaard BG (2009) Markers of early disease and prognosis in COPD. Int J Chron Obstruct Pulmon Dis 4: 157-167.

16. Ober C, Yao TC (2011) The genetics of asthma and allergic disease: a 21st century perspective. Immunol Rev 242: 10-30.

17. Mischak H, Apweiler R, Banks RE, Conaway M, Coon J, et al. (2007) Clinical proteomics: A need to define the field and to begin to set adequate standards. Proteomics Clin Appl 1: 148-156.

18. Penque D, Mendes F, Beck S, Farinha C, Pacheco P, et al. (2000) Cystic fibrosis F508del patients have apically localized CFTR in a reduced number of airway cells. Lab Invest 80: 857-868.

19. Roxo-Rosa M, da Costa G, Luider T, Scholte B, Coelho A, et al. (2006) Proteomic analysis of nasal cells from cystic fibrosis patients and non-cystic fibrosis control individuals: search for novel biomarkers of cystic fibrosis lung disease. Proteomics 6: 2314-2325.

20. Gomes-Alves P, Imrie M, Gray RD, Nogueira P, Ciordia S, et al. (2010) SELDITOF biomarker signatures for cystic fibrosis, asthma and chronic obstructive pulmonary disease. Clin Biochem 43: 168-177.

21. Simões T, Charro N, Blonder J, Faria D, Couto FM, et al. (2011) Molecula profiling of the human nasal epithelium: A proteomics approach. J Proteomics 75: 56-69.

22. Casado B, Pannell L, ladarola P, Baraniuk J (2005) Identification of human nasal mucous proteins using proteomics. Proteomics 5: 2949-2959.

23. Lee JY, Byun JY, Lee SH (2009) Proteomic analysis of normal human nasal mucosa: establishment of a two-dimensional electrophoresis reference map. Clin Biochem 42: 692-700.

24. Min-man W, Hong S, Zhi-qiang X, Xue-ping F, Chang-qi L, et al. (2009) Differential proteomic analysis of nasal polyps, chronic sinusitis, and normal nasal mucosa tissues. Otolaryngol Head Neck Surg 141: 364-368.

25. Tam A, Wadsworth S, Dorscheid D, Man SF, Sin DD (2011) The airway epithelium: more than just a structural barrier. Ther Adv Respir Dis 5: 255-273.

26. Proud D, Leigh R (2011) Epithelial cells and airway diseases. Immunol Rev 242: 186-204.

27. Holgate ST (2011) The sentinel role of the airway epithelium in asthma pathogenesis. Immunol Rev 242: 205-219.

28. Regamey N, Jeffery PK, Alton EW, Bush A, Davies JC (2011) Airway remodelling and its relationship to inflammation in cystic fibrosis. Thorax 66 624-629.

29. Bourdin A, Gras D, Vachier I, Chanez P (2009) Upper airway x 1: allergic rhinitis and asthma: united disease through epithelial cells. Thorax 64: 999-1004. 
Citation: Simões T, Charro N, Alexandre BM, Penque D (2012) Proteomics in Detection and Monitoring Chronic Lung Diseases: The Human Nasal Epithelium as a Molecular Model. J Aller Ther S7:004. doi:10.4172/2155-6121.S7-004

30. Passalacqua G, Ciprandi G, Canonica GW (2001) The nose-lung interaction in allergic rhinitis and asthma: united airways disease. Curr Opin Allergy Clin Immunol 1: 7-13.

31. Serrano C, Valero A, Picado C (2005) [Rhinitis and asthma: one airway, one disease]. Arch Bronconeumol 41: 569-578.

32. Rimmer J, Ruhno J (2006) 6: Rhinitis and asthma: united airway disease. Med J Aust 185: 565-571.

33. Braunstahl G (2007) The united airways concept: from bench to bedside Monaldi Arch Chest Dis 67: 95-101.

34. Compalati E, Ridolo E, Passalacqua G, Braido F, Villa E, et al. (2010) The link between allergic rhinitis and asthma: the united airways disease. Expert Rev Clin Immunol 6: 413-423.

35. Chapman AL, Morrissey BM, Vasu VT, Juarez MM, Houghton JS, et al. (2010) Myeloperoxidase-dependent oxidative metabolism of nitric oxide in the cystic fibrosis airway. J Cyst Fibros 9: 84-92.
36. Thomson E, Brennan S, Senthilmohan R, Gangell CL, Chapman AL, et al. (2010) Identifying peroxidases and their oxidants in the early pathology of cystic fibrosis. Free Radic Biol Med 49: 1354-1360.

37. Mark M, Ghyselinck NB, Chambon P (2006) Function of retinoid nuclear receptors: lessons from genetic and pharmacological dissections of the retinoic acid signaling pathway during mouse embryogenesis. Annu Rev Pharmacol Toxicol 46: 451-480

38. Merkel D, Rist W, Seither P, Weith A, Lenter MC (2005) Proteomic study of human bronchoalveolar lavage fluids from smokers with chronic obstructive pulmonary disease by combining surface-enhanced laser desorption/ionizationmass spectrometry profiling with mass spectrometric protein identification. Proteomics 5: 2972-2980.

39. Gray RD, MacGregor G, Noble D, Imrie M, Dewar M, et al. (2008) Sputum proteomics in inflammatory and suppurative respiratory diseases. Am J Respir Crit Care Med 178: 444-452. 